\title{
Eletrobras management program in ergonomics: the pursuit of excellence through maturity levels
}

\author{
Paulo Roberto de Oliveira Bassil Pires ${ }^{\mathrm{a}, *}$ and Fagner Fagundes Rezende ${ }^{\mathrm{a},{ }^{* *}}$ \\ ${ }^{a}$ Division of Occupational Safety Engineering, Department of General Administration, Centrais Elétricas \\ Brasileiras S.A. - Eletrobras, Rio de Janeiro, RJ, Brazil
}

\begin{abstract}
Ergonomics for Eletrobras arose from the need in having an environment more suitable to the characteristics and circumstances of employees, in compliance with Regulation Standard no. 17 - Ergonomics (NR17) of the Ministry of Labor and Employment. Being a mixed economy company with regionalized anthropometric characteristics of its employees, the study of ergonomic adjustments and improvement of the concept of Ergonomics were and have been of great importance to the company's production environment. These advances have contributed to the development of specific technical criteria for the purchase of furniture and work tools (accessories), apart from their possible effects on the user. Ergonomics has been perceived as a technical-scientific tool, aimed to study labor interactions, new technologies and specific characteristics of the activities performed. To meet these demands a multidisciplinary Ergonomics Committee was created in Eletrobras, and effectively established the Ergonomics Management Program in the company; This program is marked by well-defined phases with great success in making use of these studies for other types of corporate activities and also facilitating the program control and its maturity levels, even at a business level.
\end{abstract}

Keywords: Management Program in Ergonomics, Eletrobras Ergonomics Committee, ergonomic mapping, epidemiological profile, maturity levels

\section{Introduction}

In order to comply with the existing standards and labor laws, Eletrobras began to develop activities focused on Ergonomics in 2002. Back then a committee was established with an emphasis on health professionals - all trained in ergonomics funded by the company - to address health issues and try to improve the quality of the work environment.

These pioneer employees worked extensively for some time, including participating in an ergonomic mapping carried out across the company within two years, under the technical supervision of the Fundação Comitê de Gestão Empresarial (FUNCOGE) - Foundation Committee of Business Management.

However, it was only in 2007, after the initiative of these precursors in providing support to the implementation of technical specification for the purchase of chairs (with ergonomic adjustment features) for all employees, that the need for standardization of duties and formalization of Eletrobras Ergonomics Committee (EEC) structuring was observed.

Since then the work has increased in quantity and quality, as the multidisciplinary and technical nature of this committee confer the same status as an advisory body within the company - as defined in Resolution of the Executive Board of Eletrobras - for purchases of several products, services and improvements, which influence direct and/or indirectly the suitability of jobs for employees (always observing the specific activities carried out).

Currently composed of qualified workers in several areas (Occupational Safety Engineering, Architecture, Information Technology, Nursing, Administration, among others), EEC has the valuable advisory and direct intervention of an Ergonomics Expert hired to do assessments and technical reports

\footnotetext{
* Corresponding Author. Mailing address: Avenida Marechal Floriano $19-17^{\circ}$ andar, Centro - Rio de Janeiro, RJ - Brasil - CEP: 20.080-003; E-mail:paulo.pires@eletrobras.com;

** Outsourced Consultant - Human Factors Professional;
} 
of the various requests received by this committee, and also guide their actions. In addition, EEC is institutionally connected to the Division of Occupational Safety Engineering (DAAT), which is also the area responsible for occupational safety and health of Eletrobras.

With this structure, EEC has been working and acting in pursuit of excellence, aiming to protect workers when it comes to Ergonomics, knowing that it is a discipline that deals with the understanding of interactions between humans and other elements of a system; it is the profession that applies theory, principles, data and methods, to projects aimed at human welfare and performance of systems [1].

Based on that, Eletrobras Management Program in Ergonomics (PEGE) was created with well-defined phases, in which specific criteria have been and are still observed in order to view, qualify and quantify their maturity levels: becoming one of the essential points for non-stagnation of the program, as well as a form of constant evaluation.

\subsection{Genesis of Eletrobras management program in ergonomics (PEGE)}

Taking into account the background to commencement of works - marked by an empirical assessment of the buildings occupied by the company - PEGE was not initially designed or intended to be developed the way it really was, but due to planned factors that interfere with the course of its unfolding PEGE was cast to be developed in phases of direct action, which allowed the analysis of the whole process to be better implemented and utilized.

We highlight such phases as follows:

\subsubsection{Phase 1-Ergonomic mapping}

In the pre-project, a study was conducted in all buildings occupied by Eletrobras, contemplating structural, organizational, cognitive, furniture and activity aspects, used or absorbed by employees throughout their work activity. This assessment focused on a comprehensive survey through a broad overview of activities (administrative sectors), that, in a sense, are homogeneous, however, individuality of the tasks were taken into account, analyzing and comparing the prescribed manner and actual way they were performed.

\subsubsection{Phase 2 - Epidemiological profile}

At this stage a survey was conducted with the employees of the company, with the goal to map the main pain complaints (including intensity and duration of pain) - at this time not relating such complaints to the activities carried out (causal). This particular group was called the Symptomatic Group (SG).

\subsubsection{Phase 3-Specific conduct}

After the previous phase was set, a specific conduct for preventive work was developed (primary and secondary) with the SG, with the main focus on physiological effects of stretching and strengthening of muscles (and respective annexes) mapped.

Complementing the activities of prevention, reports were developed outlining the possible nexus of complaints with the activities performed by assessed employees (Assessment of Simplified Causal Nexus - ASCN). This evaluation aimed primarily the understanding of the burdens evidenced in SG, which allowed us to carefully outline its possible nexus: in this stage, monitoring and controlling their results individually.

\subsubsection{Phase 4-PEGE maturity}

Upon the success of previous phases, EEC was consolidated and well regarded in the company, undertaking the responsibility for the program as a whole, because, according to Couto, the committee is the great articulator of the actions of Ergonomics [2].

The structure of the program, the multidisciplinary expertise of the members, the institutionalization and consolidation of this group by the Board of Directors of the company and the discussions on the subject at the corporate level, granted EEC advisory power within the company - with an active role in various work activities and in the analysis of direct and/or indirect impacts on the activity of the employee.

At this stage the maturity levels, adapted from the CMMI - Capability Maturity Model Integration developed by the Software Engineering Institute (SEI) were discussed as criteria for evaluation and monitoring of the program [3].

The adaptations made in this model were necessary for the optimization of the maturity process, actually evaluating to which the extent the specific process to meet the program is well defined, managed and controlled. This process involves having a potential for consistent growth, applying these results in other projects of the organization. The maturity levels need to be clearly understood so that process optimization happens naturally: 


\subsubsection{Maturity level 1-Initial}

This first level is used whenever there is no control mechanism or even planning: it is a level of deployment or early labor. At this early stage, some methods and practices are developed; and the development processes are poorly defined. Proper methods are used and project management is incipient.

\subsubsection{Maturity level 2 -Repeatable}

This subsequent level is recognized by the importance of a better environment - so that you can replicate successful practices in the program. The planning of future actions begins to occur efficiently and meeting deadlines.

At this moment we identify the problems of project control. At this level we can clearly identify some of the main routines:

- Management of demands;

- Management of program activities plan;

- Monitoring and inspection of the program progress;

- Managing the manpower participating in the program;

- Quality management of the program;

\subsubsection{Maturity level 3 - Defined}

It is highlighted by the development of a strong corporate culture. In our case, based on ergonomics specially aimed at prevention - using common processes and sharing lessons learned.

At this level the emphasis is on the interaction between the program itself and the organization. Some major tasks begin to appear, such as:

- Establishment of a group responsible for program activities;

- Creating an organization for establishing and maintaining a set of processes in order to meet the program;

- Establishment of a training plan with the purpose of developing the vision and critical awareness of the program;

- Integration between different areas within a coherent process;

- Development of actions, together with the various departments, seeking to improve the scope and performance of the program as a whole;

- Direct analysis of all actions, at the corporate level, to identify problems and measure their effectiveness;

\subsubsection{Maturity level 4 - Managed}

Once the previous level is completed, there is greater ease in obtaining statistical markers in order to characterize the performance of the program, further stimulating the involvement of everyone in it and also improving prediction of outcomes.

In this phase the quality of the program and its results are assessed and some main features can be identified:

- Management of quantitative process to control the performance of the program;

- Optimized management of program quality;

\subsubsection{Maturity level 5-Optimized}

At this stage there is a quest for continuous improvement of results through the multidisciplinary approach learning every subject related to the program.

There is also the constant interpretation and measurement of results. At this point, in which the program is already consolidated and acknowledged in the company, the plans have certain characteristics and any decision making, however risky it may seem, is calculated within a margin of safety.

The main characteristics of this stage are:

- Development of actions which allow possible changes, but avoid losses in quality of the program;

- Establishment of procedures to identify changes in the applicability and transfer them to EEC (program manager);

\section{Role of the human factors professional in PEGE}

The Human Factors Professional has a direct interference in all parts of the program. Playing the role of consultant, they act as a bridge between EEC and the employees, and provide any technical and specific background (due to the expertise of activity) for the performance of the committee on activities and routines of the company to be always as efficient and as quickly as possible.

As a practical discipline, according to Vidal, Ergonomics seeks to appoint appropriate solutions to users and operators and to the reality of companies and organizations [1].

In this scenario, the performance of Human Factors Professional is evidenced through the following activities:

- Evaluate the workstations and/or workplaces and specific activities of employees, always highlighting the situations encountered and 
recorded by video or photographs (production of evidence);

- Through the direct line of communication between the employee and EEC (a specific mail box to which employees forward their demands related to ergonomics and related issues: ergonomia@eletrobras.com - known internally as PROJ-ergonomia), this professional quickly assess the complaints reported;

- Specific study with the architecture area of the company to change layouts, turning them productive - at the request of the organizational units - based upon current legislation, ensuring compliance thereto;

- Also with the architecture team, a study of accessibility and design of specific adaptations to people with special needs is carried out;

- Evaluation and development of technical specifications for the acquisition of equipment, services, accessories and other contracts that may influence direct or indirectly in terms of ergonomic activity of the employee;

- Monitoring and inspection of physical measurements (temperature, light, noise, among others) made through the Program for Prevention of Environmental Risks (PPRA), together with the Service Specialized in Safety Engineering and Occupational Health (SESMT);

These highlighted activities are the major activities developed by ergonomics professional. However, many other benefits result from the presence of this professional in Eletrobras: the main one was the consolidation and maintenance of a new corporate culture much more concerned and focused on prevention issues (which also involves other areas besides the ergonomics, but mainly with regard to occupational safety and health), since these measures, today, are seen as investment rather than expenditure.

There is a strong tendency that measures like these (grounded in this new way of thinking) are expanded, giving the employee a lot more quality in the workplace - which unfolds in securing the performance of work activities and considerable improvement in the performance of each employee.

\section{Results obtained with PEGE}

We cannot talk about PEGE without mentioning the work and the positive results obtained by the commission that led to EEC, because even without the proper required infrastructure, pioneer employees made an excellent job, and therefore PEGE is now a credible program recognized and approved in Eletrobras.

With the improvement of the work started several years ago and the current phase in which PEGE is, we can see that within this philosophy that considers the cost of the actions held as investment, the cost/benefit ratio of PEGE is extremely favorable to the very continuity of the program, as can be seen in the analysis of Table 1:

Table 1

Comparative: costs of PEGE X cost Consolidated operating costs/expenses and net income - year 2010

\begin{tabular}{|c|c|c|c|c|c|}
\hline Purchases/Services & $\begin{array}{l}\text { Expenditure by } \\
\text { sector (R\$) }\end{array}$ & $\begin{array}{l}\text { Expenditure by } \\
\text { sector / Total } \\
\text { expenditure }(\%)\end{array}$ & $\begin{array}{l}\text { Costs/Operating } \\
\text { Expenses (R\$) }\end{array}$ & Net Income (R\$) & $\begin{array}{l}\text { Expenditure/ } \\
\text { Consolidated } \\
\text { Costs (\%) }\end{array}$ \\
\hline $\begin{array}{l}\text { Purchase of accessories with } \\
\text { ergonomic features }\end{array}$ & $236,000.00$ & 71.08 & \multirow{3}{*}{$3,465,000,000.00$} & \multirow{3}{*}{$2,248,000,000.00$} & 0.00681 \\
\hline Ergonomics Consulting & $96,000.00$ & 28.92 & & & 0.00277 \\
\hline PEGE (Total expenditure) & $332,000.00$ & 100.00 & & & 0.00958 \\
\hline
\end{tabular}

Note that, in 2010, PEGE consumed in all, less than $0.01 \%$ of total amount spent on operating expenses of Eletrobras - which is negligible on the proven benefits of the program. Through consistent and thorough work of its members, through the management of the PEGE, EEC has conquered significant attributes and representation in the company's employees, and also with the senior management of Eletrobras - so that their duties were ratified and membership was recently expanded with a new Executive Board Resolution.

Among the main achievements, the most significant will be highlighted throughout this chapter. 


\subsection{Change in layout}

The partnership with the architecture team of the company is strengthened, as the architect in charge of the production of layouts readily accepted the invitation and is currently a member of EEC. Moreover, the managing organizational unit of EEC and the architecture area are within the same department, which facilitates this interaction.

Thus, decisions involving changes in layout are backed by the entire staff of EEC, and the approval of the Human Factors Professional, reinforcing the idea that it is better to invest in a productive and efficient layout than cause successive rework.

\subsection{Technical specifications}

With the expertise acquired over time, as we gained respect and credibility due to successful actions, EEC received the assignment to develop technical specifications of objects, goods, accessories, equipment and/or services that may interfere directly in the employment/activity performed relation, such as furniture and accessories with ergonomic features, among others.

Such an assignment has already been tested in the bidding process for procurement of work chairs, plus the purchase of articulated brackets for LCD/LED screen - both benefited all employees. So you can see the performance of EEC in the daily functioning of the company.

There was even request of these specifications produced by EEC by companies working together with Eletrobras, in order to give service providers the most adequate conditions of work and an efficient adaptation.

\subsection{Individual ergonomic assessments}

The acquisition of appropriate furniture and ergonomic accessories (that meet the majority of employees) does not guarantee success in the design of workstations, since each worker is a different and unique being. Thus, understanding the demands of each individual in the development of their work activities becomes increasingly a mainstay of the program, and EEC has achieved this level.

Other factors also differ in the assessments, such as the actual activities performed by the employee, the local light level, exposure time, and many others. The most important thing is to properly perform adaptations to the workstation of the employee, respecting the individual characteristics and demands observed, having as parameter the NR17.

A formalized assessment, when necessary, in the form of a technical report brings satisfaction and safety to the employee, providing approval for the solution of inadequacy to be readily implemented. In these cases, the opinion is signed by EEC coordinator and the Human Factors Professional, and then forwarded to the employee with a copy to those involved (including the employee's boss) for taking appropriate action.

\subsection{Accessibility and persons with physical disabilities}

One of the activities most recently integrated into the EEC is a study in partnership with specialized institutions on accessibility and inclusion of people with physical disabilities in Eletrobras. In practice, the object of study can be summarized in two situations: the Eletrobras employee and the outsourced employee.

The study and its application in practice need to consider these two situations, as Eletrobras is a mixed capital company and entering its workforce is only possible through public contest. On the other hand, there is tremendous interest in the social responsibility area of the company in achieving the social inclusion of people with disabilities in outsourced services contracts, a measure that meets the current public policies.

Struggling to establish this scenario, EEC has carried out specific actions for the benefit of new employees hired: different situations involving multiple parameters and different types of limitations, such as visual and motor. In addition to working specifically in the workstation, the focus also turns to the surrounding areas, such as facilities on the common area frequented by the employee, as well as the more accessible company areas.

The committee, motivated by this new activity, will expand their coverage area and integrate new strategies with regard to the approach of employees (relationship between all and the deal with disabled individuals) and ergonomic evaluation itself (more specifically any physical disability and consequent problems). 


\subsection{Design: construction of the new offices for Eletrobras}

In order to practice excellence in ergonomics, this being one of the most valuable aspects of this science and a PEGE pillar, EEC is inserted as an advisory body in the design project for the new offices of Eletrobras, discussing it with institutions hired for this purpose - an evidence of investment starting correctly to avoid rework and further spending.

Thought and concern about occupational safety and health of the employees will be taken carefully including discussion of various points related to layout and accessibility - overseeing the whole project, which will also count with the help of other sectors of the company, remarkable in their activities, as the area of energy efficiency, developing a multifaceted program across the country and in different segments of society.

Consider the design of an entire work environment, from the foundations to the interface objects of the activities will not be a simple task, but certainly EEC is prepared to undertake this responsibility in view of the sobriety and seriousness of the group.

\section{Conclusions}

After this investigation of the work carried out by EEC, the strategic level where it is now is obvious, so that constant improvement of PEGE must be observed and closely monitored by all as it will have a direct impact on the company's activities.

Understanding that there are levels to be achieved is an integral part of the learning process. Difficulties will arise at many different times and under various formats. However, EEC remains steadfast in its purpose of raising more and more the value of Ergonomics in culture and experience of Eletrobras employees.

In this way, as the maturity levels are achieved and exceeded, there will be a definition of the new way to follow. The practicality of the principles, strength and safety in the establishment of criteria appropriate to the company's activities and the detailed analysis of the physical structure and employee of the corporation are fundamental values for the success of the program.

It is not possible to conduct a program of this magnitude without the presence of Human Factors Professionals to guide actions and provide technical inputs as required for the work of the committee. Would be so much better than the experts were employees of the company, but if it does not, their interaction with employees must be unconstrained, promoting efficiency and transparency of the work.

With the support of the company's board, appropriate training, tenacity of the EEC members, the work will be developed properly, reaching directly the employees - greatest beneficiaries. Therefore the company, funding the project, will be the greatest indirect beneficiary from the results of a safe, comfortable working environment, from where they obtain an efficient performance.

\section{Acknowledgments}

Acknowledgements for this work range from the members of EEC to the Eletrobras Executive Board for their efforts and support, also to each employee and outsourced worker served by the program and involved with our activities.

\section{References}

[1] M.C. VIDAL, Ergonomia na empresa (Ergonomics in the company): Útil, prática e aplicada (Useful, practical and applied), ( $2^{\text {nd }}$ edition), Editora Virtual, Rio de Janeiro, (2002), 14-18.

[2] H.A. COUTO, Como instituir a Ergonomia na empresa (How to implement Ergonomics in the company): A prática dos Comitês de Ergonomia (The practice of Ergonomics Committees), ( $2^{\text {nd }}$ edition), Ergo Editora, Belo Horizonte, (2011), 51.

[3] International Centre for Software Technology (CITS). http://www.cits.br/cmmi.do (accessed in September 2010). Also available in http://pt.wikipedia.org/wiki/CMMI (accessed in November 2010). 